\title{
Dynamics of the internal reaction layer arising during carbonation of concrete
}

\author{
S. A. Meier ${ }^{\mathrm{a}, *}$, M. A. Peter ${ }^{\mathrm{a}}$, A. Muntean ${ }^{\mathrm{a}}$ and M. Böhm ${ }^{\mathrm{a}}$ \\ ${ }^{\text {a }}$ Centre for Industrial Mathematics, FB 3, University of Bremen, \\ Postfach 330 440, 28334 Bremen, Germany
}

\begin{abstract}
Carbonation is the reaction of environmental carbon dioxide with alkaline species in concrete. It is one of the major degradation mechanisms affecting the durability of reinforced concrete structures. In this paper, a mathematical model of the carbonation process is formulated and simulated using the finite-element method. Nonlinear reaction rates, Robin boundary conditions and a decrease of the concrete porosity in time are taken into account. A dimensional analysis based on a nondimensionalisation of the entire model is introduced to identify the key parameters and the different characteristic time and length scales of the whole process. Numerical simulations show the occurrence of an internal reaction layer travelling through the material. The speed and the width of the layer are rigorously defined via dimensionless quantities. A parameter study shows that the speed and the width are strongly related to the size of the Thiele modulus which is typically large. The relevance of other parameters is also investigated. The model is validated for accelerated and natural carbonation settings.
\end{abstract}

Key words: Reaction layer, concrete carbonation, diffusion, Thiele modulus, mathematical modelling, simulation

PACS: 82.20.Wt, 82.40.Ck, 81.05.Rm, 02.70.Dh

\section{Introduction}

The carbonation of concrete is one of the major physicochemical processes that can limit the lifetime of reinforced concrete structures by reducing the

\footnotetext{
* Corresponding author.

Email addresses: sebam@math.uni-bremen.de (S. A. Meier), mpeter@math . uni-bremen.de (M. A. Peter), muntean@math. uni-bremen.de (A. Muntean), mbohm@math.uni-bremen.de (M. Böhm).
} 
protection of the interior steel bars from corrosion. This process is caused by atmospheric carbon dioxide reacting mainly with calcium hydroxide available in the highly alkaline pore solution $(\mathrm{pH} \approx 14)$. As soon as the $\mathrm{pH}$ level decreases, the microscopic oxide layer at the steel reinforcements disappears and the steel bars can corrode. The rusting of the reinforcement leads to a severe reduction of the durability of the structure. The carbonation process is mainly determined by the reaction mechanism

$$
\mathrm{CO}_{2}(g \rightarrow a q)+\mathrm{Ca}(\mathrm{OH})_{2}(s \rightarrow a q) \rightarrow \mathrm{CaCO}_{3}(a q \rightarrow s)+\mathrm{H}_{2} \mathrm{O},
$$

accompanied by molecular diffusion of the participating species. The overall process can be summarised as follows: The atmospheric carbon dioxide diffuses through the unsaturated concrete matrix and dissolves into the pore water. At some distance from the surface, it is consumed by calcium hydroxide which is available in the pore solution by dissolution from the solid matrix. Free water and calcium carbonate are the main products of reaction (1). Once it is built up, calcium carbonate quickly precipitates to the solid matrix. For detailed surveys and literature accounts on the carbonation process see, for instance, Taylor (1997); Bier (1988); Kropp (1995); Chaussadent (1999) and Sisomphon (2004).

From a modelling point of view, one of the main features of reaction-diffusion processes in concrete materials is the occurrence of several characteristic time and length scales. For the carbonation process, experimental evidence shows that the characteristic time scales of the carbonation reaction, precipitation and dissolution reactions are of strongly different magnitude, and hence, different significance when compared to the characteristic diffusion time of $\mathrm{CO}_{2}(\mathrm{~g})$. In particular, the carbonation reaction is usually very fast compared with the diffusive transport of $\mathrm{CO}_{2}$. This implies that wherever $\mathrm{CO}_{2}$ and $\mathrm{Ca}(\mathrm{OH})_{2}$ coexist, the carbonation reaction depletes both of them rapidly until only one is left. This leads to the creation of a narrow reaction layer, in which the bulk of the reaction (1) is located. This layer progresses into the material with a certain speed and a certain width. Thereby, it spatially separates the carbonated from the uncarbonated part of the concrete. This pattern is experimentally observed (cf. Chaussadent (1999), e.g.).

Several computational models of the carbonation process have been introduced, amongst others, by Saetta et al. (1995); Steffens et al. (2002); Papadakis et al. (1989), and van Balen and van Gemert (1994). A two-scale approach has also been discussed in Meier et al. (2005a). Most of these models are rather complex and involve a huge amount of parameters. For this reason, the mechanisms which control the shape and the dynamics of the reaction layer are not very well understood. Important questions are: Which processes drive the reaction layer forward? How is its width related to the model parameters? Can the layer be approximated by a sharp front? The present paper is concerned 
with the investigation of the dynamics of this reaction layer by means of a relatively simple carbonation model which follows the lines of Steffens (2000); Papadakis et al. (1989). In particular, we do not account for the effect of drying and wetting phases on the carbonation process, which can be important under certain conditions, as well as on the carbonation of other phases like $\mathrm{CSH}, \mathrm{CAH}, \mathrm{NaOH}, \mathrm{KOH}, \mathrm{Mg}(\mathrm{OH})_{2}$ etc.

The main difficulty in obtaining a reliable prediction model is the huge amount of parameters determining the overall process which are generally unknown. A dimensional analysis often yields useful information on the key parameters. We therefore perform a nondimensionalisation of the entire model, based on the study of Papadakis et al. (1989). For similar approaches, the reader is referred to Ishida and Wen (1968); Froment and Bischoff (1990); Weber and DiGiano (1996); Muntean (2006). In this context, an important issue is the definition of the position and width of the layer by means of the dimensionless concentration profiles. We further investigate the influence of the Thiele modulus, which relates the characteristic time of the carbonation reaction to a characteristic diffusion time, and other dimensionless numbers by a parameter study, using finite-element simulations of the model. In this paper, we report on our main observations and refer the interested reader to Meier et al. (2005) for more simulation details and to Peter et al. (2006) for a more complex model involving several carbonatable species.

Non-standard features of our model are the use of Robin boundary conditions as well as the incorporation of a nonlinear reaction rate and of a timedependent porosity. The majority of existing simulation approaches of the carbonation model only account for a constant porosity scenario. Some linear evolution laws for the porosity can be found in the literature; see Saeki et al. (1990); Papadakis et al. (1989); Chaussadent (1999). Here we are interested in the effects of an exponentially decreasing porosity on the carbonation progress. The reduction in porosity has been reported for concretes with Ordinary Portland Cement (OPC) in Bier (1988); Ishida et al. (2004); Saeki and Nagataki (1997), e.g. We assume that the decrease in porosity is only caused by the carbonation reaction itself due to the clinging of the precipitated carbonates to the pore walls.

The questions concerning the reaction layer in particular arise in the context of the moving-boundary methodology. Since in these models the occurrence and the dynamics of a moving internal reaction layer is postulated, it is of great importance to have a good understanding of driving forces. The carbonation layer has been modelled as a sharp-interface (Böhm et al. (2003); Muntean and Böhm (2004b)), and as a zone (Muntean and Böhm (2004a)). Various aspects of modelling, analysis and simulation of concrete carbonation via this methodology can be found in Muntean (2006); Muntean and Böhm (2006). 
The paper is organised as follows: In section 2, we concisely describe the considered carbonation scenario and formulate a mathematical model of the whole process. We describe the reaction and absorption kinetics and list the mass balances of the active species, including the boundary and initial conditions. In section 3, we discuss the most important dimensionless numbers occurring in the resulting system. Based on these dimensionless quantities, a definition of the carbonation depth and of the reaction layer is given. In section 4, we state the results of our numerical experiments. We validate our model by comparison with experimental results from both an accelerated carbonation test and a natural exposure scenario, and we show results of the parameter study (mostly with respect to the Thiele modulus). Finally, we discuss the effect of variable boundary conditions and of a decreasing porosity on the model output. We summarise the results and draw our main conclusions in section 5 .

\section{Mathematical Model}

\subsection{Geometry}

We consider a part $\Omega$ of a concrete sample which is exposed to ingress of gaseous $\mathrm{CO}_{2}$ and humidity from the environment (fig. 1). The domain $\Omega \subset \mathbb{R}^{n}$, $n=1,2$ or 3 , is chosen close to the exposed boundary $\Gamma^{\mathrm{R}}$, such that it contains the reaction layer. In the interior of the sample, $\Omega$ is bounded by $\Gamma^{\mathrm{N}}$ which is chosen such that it will never be reached by the reaction layer during the time interval of interest. At this part, no-flux conditions are prescribed for all active species in the model. The whole boundary of $\Omega$ is denoted by $\Gamma$. The outward unit normal to $\Gamma$ is denoted by the vector $\nu$.

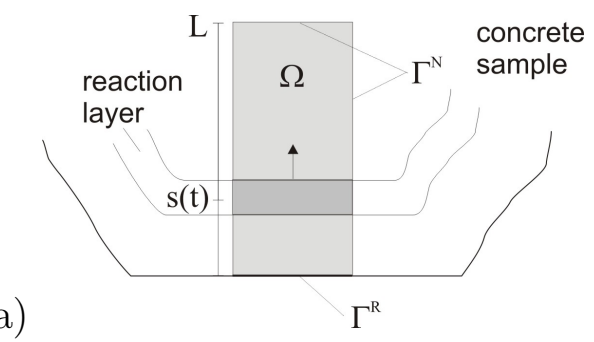

b)

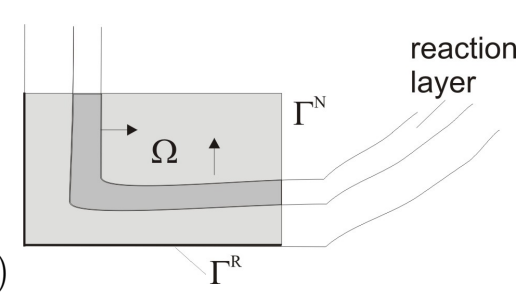

Fig. 1. Schematic view of the carbonation layer in a concrete sample. a) 1D-situation. b) 2D-situation.

We develop the mathematical model independently of the space dimension $n$. It can therefore be used for arbitrary geometries, cf. figs. 1a and 1b. However, the simulations presented in this work will be one-dimensional. Therefore, it is important to note that they can only be valuable for geometries of the type depicted in fig. 1a. 


\subsection{Porosity and volume fractions}

We introduce some concepts usually needed to describe reactive processes taking place in porous media. The region $\Omega$ is composed of the solid matrix $\Omega^{\mathrm{s}}$ and of the totality of pore voids $\Omega^{\mathrm{p}}$. Furthermore, since the pore space is unsaturated, $\Omega^{\mathrm{p}}$ typically splits into $\Omega^{\mathrm{a}}$ (the parts filled with dry air and water vapours) and $\Omega^{\mathrm{w}}$ (the parts filled with liquid water). We define the volume fractions

$$
\phi:=\left|\Omega^{\mathrm{p}}\right| /|\Omega|, \quad \phi^{\mathrm{a}}:=\left|\Omega^{\mathrm{a}}\right| /\left|\Omega^{\mathrm{p}}\right| \quad \text { and } \quad \phi^{\mathrm{w}}:=\left|\Omega^{\mathrm{w}}\right| /\left|\Omega^{\mathrm{p}}\right| .
$$

The quantity $\phi$ is called the porosity of the medium. The initial porosity $\phi_{0}$ can be calculated as

$$
\phi_{0}:=\frac{R_{\mathrm{w} / \mathrm{c}} \frac{\rho_{\mathrm{c}}}{\rho_{\mathrm{w}}}}{\left(R_{\mathrm{w} / \mathrm{c}} \frac{\rho_{\mathrm{c}}}{\rho_{\mathrm{w}}}+R_{\mathrm{a} / \mathrm{c}} \frac{\rho_{\mathrm{c}}}{\rho_{\mathrm{a}}}+1\right)},
$$

where the factors $R_{\mathrm{w} / \mathrm{c}}$ and $R_{\mathrm{a} / \mathrm{c}}$ represent the water-to-cement and aggregateto-cement ratios, while $\rho_{\mathrm{a}}, \rho_{\mathrm{w}}$ and $\rho_{\mathrm{c}}$ are aggregate, water and concrete densities, respectively (cf. Papadakis et al. (1989)).

In OPC-based concretes, an essential decrease of pore volume over time due to carbonation is often observed (Bier (1988), e.g). Therefore, the porosity cannot be assumed as constant, and hence, $\phi$ has to account for variations with respect to time. To capture this effect, we propose the exponential law

$$
\phi(t):=\phi_{0} \mathrm{e}^{-\beta \eta_{\min } t} \quad \text { for each } t \geq 0,
$$

where the quantity $\eta_{\min } \approx 1.78 \cdot 10^{-5} \mathrm{~mol} \cdot \mathrm{cm}^{-3} \mathrm{~d}^{-1}$ represents a lower bound of the carbonation kinetics (and "d" stands for days). See Muntean (2006) for a derivation of (3) via first principles. The factor $\beta$ is given by

$$
\beta:=\frac{m_{\mathrm{CaCO}_{3}}}{\rho_{\mathrm{CaCO}_{3}}}-\frac{m_{\mathrm{Ca}(\mathrm{OH})_{2}}}{\rho_{\mathrm{Ca}(\mathrm{OH})_{2}}} \approx 4.19 \mathrm{~cm}^{3} / \mathrm{mol},
$$

where $m_{\nu}$ and $\rho_{\nu}$ are molar mass and mass density of the species $\nu$, respectively. Typical values of $\phi_{0}$ are between 0.5 and 0.6 .

\subsection{Reaction-diffusion processes}

We formulate the macroscopic mass balances for $\mathrm{CO}_{2}$ in the gaseous and in the liquid phase, and for $\mathrm{Ca}(\mathrm{OH})_{2}$ and $\mathrm{CaCO}_{3}$ in the liquid phase. For the numerical values of the model parameters that are given in the sequel, we refer to Steffens (2000); Papadakis et al. (1989). We denote by $c_{\mathrm{CO}_{2}(g)}, c_{\mathrm{CO}_{2}}$, 
$c_{\mathrm{Ca}(\mathrm{OH})_{2}}$ and $c_{\mathrm{CaCO}_{3}}$ the mass concentrations of $\mathrm{CO}_{2}$ in the air phase, and $\mathrm{CO}_{2}, \mathrm{Ca}(\mathrm{OH})_{2}, \mathrm{CaCO}_{3}$ in the liquid phase, respectively. All concentrations are intrinsic concentrations, that is they express the mass of the species per phase volume.

We consider the kinetics of the carbonation reaction described by a power-law with a humidity-dependent multiplier (Steffens (2000); Saetta et al. (1995)). The reaction rate in $\mathrm{mol} /\left(\mathrm{d} \cdot \mathrm{cm}^{3}\right)$ is defined as

$$
f^{\text {reac }}:=C^{\text {reac }} g^{\text {hum }}(\mathrm{RH}) c_{\mathrm{CO}_{2}}^{p} c_{\mathrm{Ca}(\mathrm{OH})_{2}}^{q},
$$

where $p, q \geq 1$ are the partial reaction orders and $C^{\text {reac }}$ is the reaction constant for carbonation. The factor $g^{\text {hum }}(\mathrm{RH})$ describes the dependence of the reaction on the relative humidity $\mathrm{RH}$ and can be written as

$$
g^{\text {hum }}(\mathrm{RH})= \begin{cases}0, & \mathrm{RH} \leq 0.5 \\ 5 / 2(\mathrm{RH}-0.5), & 0.5<\mathrm{RH} \leq 0.9 \\ 1, & \mathrm{RH}>0.9\end{cases}
$$

The widely used reaction orders are $p=q=1$ (Steffens (2000); Ishida and Maekawa (2001); Chaussadent (1999)). For the simulations, we therefore choose $p=q=1$. See also Muntean and Böhm (2004b) for a discussion on the choice of $p$ and $q$ and for a preliminary investigation of the model stability, when different reaction kinetics are supposed to drive partially-carbonated zones.

We assume that a linear exchange term due to absorption of $\mathrm{CO}_{2}(g)$ is given by

$$
f^{\text {Henry }}:=C^{\text {ex }}\left(C^{\text {Henry }} c_{\mathrm{CO}_{2}(g)}-c_{\mathrm{CO}_{2}}\right) .
$$

The dimensionless Henry constant $C^{\text {Henry }}$ depends on temperature. For $\vartheta=$ $20^{\circ} \mathrm{C}$, it is $C^{\text {Henry }}=0.82$.

The mass balances of the active species in $\Omega$ can now be written as

$$
\begin{aligned}
& \partial_{t}\left(\phi \phi^{\mathrm{a}} c_{\mathrm{CO}_{2}(g)}\right)-\nabla \cdot\left(D_{\mathrm{CO}_{2}(g)} \phi \phi^{\mathrm{a}} \nabla c_{\mathrm{CO}_{2}(g)}\right)=-f^{\text {Henry }} \text {, } \\
& \partial_{t}\left(\phi \phi^{\mathrm{w}} c_{\mathrm{CO}_{2}}\right)-\nabla \cdot\left(D_{\mathrm{CO}_{2}} \phi \phi^{\mathrm{w}} \nabla c_{\mathrm{CO}_{2}}\right) \\
& =f^{\mathrm{Henry}}-m_{\mathrm{CO}_{2}} \phi \phi^{\mathrm{w}} f^{\mathrm{reac}}, \\
& \partial_{t}\left(\phi \phi^{\mathrm{w}} c_{\mathrm{Ca}(\mathrm{OH})_{2}}\right)-\nabla \cdot\left(D_{\mathrm{Ca}(\mathrm{OH})_{2}} \phi \phi^{\mathrm{w}} \nabla c_{\mathrm{Ca}(\mathrm{OH})_{2}}\right) \\
& =-m_{\mathrm{Ca}(\mathrm{OH})_{2}} \phi \phi^{\mathrm{w}} f^{\mathrm{reac}} \text {, } \\
& \partial_{t}\left(\phi \phi^{\mathrm{w}} c_{\mathrm{CaCO}_{3}}^{\mathrm{w}}\right)=m_{\mathrm{CaCO}_{3}} \phi \phi^{\mathrm{w}} f^{\mathrm{reac}} .
\end{aligned}
$$

The diffusivities $D_{\nu}$ are not effective ones. They refer to the micro-scale and incorporate a tortuosity factor. The volume fractions $\phi, \phi^{\mathrm{w}}$ and $\phi^{\mathrm{a}}$ can depend on time. To keep the model simple, we assume them to be a priori given. 
Note that a possible coupling of the moisture produced by reaction and the transport parameters is neglected, even though this effect is known to be important for a precise prediction of the carbonation process (see van Balen and van Gemert (1994); van Balen (2005), e.g.). However, in this paper we aim at studying the principal behaviour of the model output, in particular the qualitative properties of the internal reaction layer. Therefore, we leave the inclusion of additional nonlinearities for future work and only remark that the modelling strategy presented here is conceptually capable of including such effects. Detailed descriptions of the modelling aspects can be found in Meier et al. (2005); Muntean (2006).

At the exposed boundary $\Gamma^{\mathrm{R}}$, we assume an exchange of $c_{\mathrm{CO}_{2}(g)}$ with the atmospheric concentration $c_{\mathrm{CO}_{2}(g)}^{\mathrm{ext}}$ by

$$
-\left(D_{\mathrm{CO}_{2}(g)} \phi \phi^{\mathrm{a}} \nabla c_{\mathrm{CO}_{2}(g)}\right) \cdot \nu=C_{\mathrm{CO}_{2}(g)}^{\mathrm{Rob}}\left(c_{\mathrm{CO}_{2}(g)}-c_{\mathrm{CO}_{2}(g)}^{\mathrm{ext}}\right) \quad \text { at } \Gamma^{\mathrm{R}} .
$$

The system is completed by no-flux conditions for $c_{\mathrm{CO}_{2}(g)}$ at $\Gamma^{\mathrm{N}}$ and for the remaining diffusing species at the entire boundary, and by the initial conditions

$$
\begin{gathered}
c_{\mathrm{CO}_{2}(g)}(x, 0)=c_{\mathrm{CO}_{2}(a q)}(x, 0)=c_{\mathrm{CaCO}_{3}}(x, 0)=0, \\
c_{\mathrm{Ca}(\mathrm{OH})_{2}}(x, 0)=c_{\mathrm{Ca}(\mathrm{OH})_{2}}^{0}, \quad x \in \Omega .
\end{gathered}
$$

\subsection{Transport of moisture}

Moisture appears in the pores as vapour and as (liquid) water. We assume an equilibrium between the two phases. The amount of moisture produced by reaction (1) can therefore be described by a single variable. The transport of the moisture produced by reaction is modelled by a diffusion-like equation for the total mass concentration $w$ of water, as was derived in Steffens (2000); Grunewald (1997), e.g. The variable $w$ refers to the pore volume and incorporates both the liquid pore water and the vapour from the air-filled parts. The mass balance for moisture is

$$
\partial_{t}(\phi w)-\nabla \cdot\left(D_{\mathrm{H}_{2} \mathrm{O}} \phi \nabla w\right)=\phi \phi^{\mathrm{w}} m_{\mathrm{H}_{2} \mathrm{O}} f^{\text {reac }} \quad \text { in } \Omega .
$$

The equilibrium relation between $w$ and $\mathrm{RH}$ is given by the sorption isotherm $\mathrm{RH}(w)$. For values of $\mathrm{RH}$ between $50 \%$ and $80 \%$ it can be well approximated by an affine-linear function $\mathrm{RH}(w)=a+b \cdot \phi_{0} w$. The quantities $a=-0.11$ and $b=22.7 \mathrm{~cm}^{3} / \mathrm{g}$ are fitting parameters taken from Steffens (2000). Using this relation, we can express the factor $g^{\text {hum }}(\mathrm{RH})$ also as a function of $w$, $f^{\text {hum }}(w):=g^{\text {hum }}(\mathrm{RH}(\mathrm{w}))$. The initial amount of moisture in the pores is denoted by $w^{0}=w(x, 0)$. 
At the exposed boundary $\Gamma^{\mathrm{R}}$, we assume an exchange with the ambient moisture $w^{\text {ext }}$ by the Robin boundary condition

$$
-\left(D_{\mathrm{H}_{2} \mathrm{O}} \phi \nabla w\right) \cdot \nu=C_{\mathrm{H}_{2} \mathrm{O}}^{\mathrm{Rob}}\left(w-w^{\mathrm{ext}}\right) \quad \text { at } \Gamma^{\mathrm{R}} .
$$

Note that the boundary conditions (7e) and (8b) can account for different exposure scenarios by varying the coefficients $C_{\mathrm{CO}_{2}(g)}^{\mathrm{Rob}}, C_{\mathrm{H}_{2} \mathrm{O}}^{\mathrm{Rob}}$.

\section{Dimensional analysis}

In general, there is no unique guiding principle for finding an appropriate scaling for a system if many model parameters as well as different time and spatial scales are involved. See Muntean (2006); Papadakis et al. (1989) for some motivating ideas concerning scaling of the carbonation process.

We first define reasonable upper bounds for the concentrations. We additionally take into account that $\phi=\phi(t), \phi^{\mathrm{a}}=\phi^{\mathrm{a}}(t)$ and $\phi^{\mathrm{w}}=\phi^{\mathrm{w}}(t)$ can vary in time. We assume that the porosity $\phi(t)$ reaches its maximal value at $t=0$. This assumption is consistent with the law proposed in (3). If diffusion of the species in water is sufficiently slow compared to diffusion in air, then by a simple worst-case calculation we obtain the following maximal concentrations:

$$
\begin{aligned}
c_{1}^{\mathrm{m}} & :=\phi_{0} \phi^{\mathrm{a}}(0) c_{\mathrm{CO}_{2}(g)}^{\mathrm{ext}}, \\
c_{2}^{\mathrm{m}} & :=\phi_{0} \phi^{\mathrm{w}}(0) C^{\mathrm{Henry}} c_{\mathrm{CO}_{2}(g)}^{\mathrm{ext}}, \\
c_{3}^{\mathrm{m}} & :=\phi_{0} \phi^{\mathrm{w}}(0) c_{\mathrm{Ca}(\mathrm{OH})_{2}}^{0}, \\
c_{4}^{\mathrm{m}} & :=\max \left\{\frac{m_{\mathrm{H}_{2} \mathrm{O}}}{m_{\mathrm{Ca}(\mathrm{OH})_{2}}} \phi_{0} \phi^{\mathrm{w}}(0) c_{\mathrm{Ca}(\mathrm{OH})_{2}}^{0}+\phi_{0} w^{0}, \phi_{0} w^{\mathrm{ext}}\right\}, \\
c_{5}^{\mathrm{m}} & :=\frac{m_{\mathrm{CaCO}}}{m_{\mathrm{Ca}(\mathrm{OH})_{2}}} \phi_{0} \phi^{\mathrm{w}}(0) c_{\mathrm{Ca}(\mathrm{OH})_{2}}^{0} .
\end{aligned}
$$

We introduce the dimensionless quantities

$$
\begin{array}{ll}
u_{1}:=\phi \phi^{\mathrm{a}} c_{\left.\mathrm{CO}_{2}(g)\right)} / c_{1}^{\mathrm{m}}, & u_{2}:=\phi \phi^{\mathrm{w}} c_{\mathrm{CO}_{2}} / c_{2}^{\mathrm{m}}, \quad u_{3}:=\phi \phi^{\mathrm{w}} c_{\mathrm{Ca}(\mathrm{OH})_{2}} / c_{3}^{\mathrm{m}}, \\
u_{4}:=\phi w / c_{4}^{\mathrm{m}}, & u_{5}:=\phi \phi^{\mathrm{w}} c_{\mathrm{CaCO}_{3}} / c_{5}^{\mathrm{m}},
\end{array}
$$

which now depend on dimensionless time and space coordinates $\tilde{t}:=t / T$ and $\tilde{x}:=x / L$. For $L$, we choose a macroscopic length scale (the width of the sample, e.g.). As a relevant time scale $T$, we take a characteristic diffusion time for $\mathrm{CO}_{2}(g)$, which is the fastest moving species involved, namely $T:=L^{2} / D_{\mathrm{CO}_{2}(g)}$. Moreover, we define the following dimensionless parameters, which are chosen 
similarly to Papadakis et al. (1989):

$$
\begin{aligned}
& \beta_{2}:=\frac{c_{2}^{\mathrm{m}}}{c_{1}^{\mathrm{m}}}, \quad \beta_{3}:=\frac{c_{3}^{\mathrm{m}} m_{\mathrm{CO}_{2}}}{c_{1}^{\mathrm{m}} m_{\mathrm{Ca}(\mathrm{OH})_{2}}}, \quad \beta_{4}:=\frac{c_{4}^{\mathrm{m}} m_{\mathrm{CO}_{2}}}{c_{1}^{\mathrm{m}} m_{\mathrm{H}_{2} \mathrm{O}}}, \quad \beta_{5}:=\frac{c_{5}^{\mathrm{m}} m_{\mathrm{CO}_{2}}}{c_{1}^{\mathrm{m}} m_{\mathrm{CaCO}_{3}}} \\
& \delta_{2}:=\frac{D_{\mathrm{CO}_{2}}}{D_{\mathrm{CO}_{2}(g)}}, \quad \delta_{3}:=\frac{D_{\mathrm{Ca}(\mathrm{OH})_{2}}}{D_{\mathrm{CO}_{2}(g)}}, \quad \delta_{4}:=\frac{D_{\mathrm{H}_{2} \mathrm{O}}}{D_{\mathrm{CO}_{2}(g)}}, \\
& \Phi^{2}:=\frac{L^{2} m_{\mathrm{CO}_{2}}\left(c_{2}^{\mathrm{m}}\right)^{p}\left(c_{3}^{\mathrm{m}}\right)^{q}}{D_{\mathrm{CO}_{2}(g)} c_{1}^{\mathrm{m}}} C^{\mathrm{reac}} \quad(\text { Thiele modulus }), \\
& W^{\mathrm{Hen}}:=\frac{L^{2}}{D_{\mathrm{CO}_{2}(g)}} C^{\mathrm{ex}}, \quad W_{1}^{\mathrm{Rob}}:=\frac{L}{D_{\mathrm{CO}_{2}(g)}} C_{\mathrm{CO}_{2}(g)}^{\mathrm{Rob}}, \quad W_{4}^{\mathrm{Rob}}:=\frac{L}{D_{\mathrm{CO}_{2}(g)}} C_{\mathrm{H}_{2} \mathrm{O}}^{\mathrm{Rob}} .
\end{aligned}
$$

The quantities $\beta_{i}$ are usually called impact or capacity factors, whereas $\delta_{i}$ are ratios comparing each diffusivity with that of $\mathrm{CO}_{2}(g)$. The Thiele modulus $\Phi^{2}$ describes the rapidness of the carbonation reaction compared to the diffusion of gaseous $\mathrm{CO}_{2}$. The factors $W^{\mathrm{Hen}}, W_{1}^{\mathrm{Rob}}$ and $W_{4}^{\mathrm{Rob}}$ account for the rapidness of different types of interfacial mass transfer. Typical values of these parameters are shown in table 1. It can be seen that the parameters are of highly different magnitudes. For instance, $\Phi^{2}$ is large, which means that the carbonation reaction is in its fast regime. The great magnitude of the interfacialexchange numbers, $W^{\text {Hen }}, W_{1}^{\text {Rob }}$ and $W_{4}^{\text {Rob }}$ imply a strong tendency to reach the respective equilibrium state. Formally, we also list $\beta_{1}=1$ and $\delta_{1}=1$. Note that the value of $\delta_{1}$ is much greater than the other dimensionless diffusivities $\delta_{\nu}, \nu=2,3,4,5$.

Table 1

\begin{tabular}{c|c|c|c|c|c|c}
$\beta_{1}$ & $\beta_{2}$ & $\beta_{3}$ & $\beta_{4}$ & $\beta_{5}$ & $\Phi^{2}$ & $W^{\text {Hen }}$ \\
\hline 1 & 0.848 & 196 & 540 & 196 & 993 & 750 \\
\hline \hline$\delta_{1}$ & $\delta_{2}$ & $\delta_{3}$ & $\delta_{4}$ & $\delta_{5}$ & $W_{1}^{\text {Rob }}$ & $W_{4}^{\text {Rob }}$ \\
\hline 1 & $8.33 \cdot 10^{-6}$ & $8.33 \cdot 10^{-9}$ & $8.33 \cdot 10^{-4}$ & 0 & $2.50 \cdot 10^{4}$ & $2.50 \cdot 10^{6}$
\end{tabular}

Dimensionless parameters for an accelerated carbonation test (cf. section 4.1).

Employing (9) and (10), the system (7)-(8) can be formulated in terms of $u_{1}, \ldots, u_{5}$. The result is the following system:

$$
\begin{aligned}
\partial_{t} u_{1}-\Delta u_{1} & =-W^{\text {Hen }}\left(C^{\text {Henry }}\left(\phi \phi^{\mathrm{a}}\right)^{-1} u_{1}-\left(\phi \phi^{\mathrm{w}}\right)^{-1} \beta_{2} u_{2}\right), \\
\beta_{2} \partial_{t} u_{2}-\beta_{2} \delta_{2} \Delta u_{2} & =+W^{\text {Hen }}\left(C^{\text {Henry }}\left(\phi \phi^{\mathrm{a}}\right)^{-1} u_{1}-\left(\phi \phi^{\mathrm{w}}\right)^{-1} \beta_{2} u_{2}\right)-\eta^{\text {reac }}, \\
\beta_{3} \partial_{t} u_{3}-\beta_{3} \delta_{3} \Delta u_{3} & =-\eta^{\text {reac }} \\
\beta_{4} \partial_{t} u_{4}-\beta_{4} \delta_{4} \Delta u_{4} & =+\eta^{\text {reac }} \\
\beta_{5} \partial_{t} u_{5} & =+\eta^{\text {reac }}
\end{aligned}
$$

where the dimensionless carbonation reaction rate is defined by

$$
\eta^{\text {reac }}:=\Phi^{2} \cdot\left(\phi \phi_{w}\right)^{1-p-q} f^{\text {hum }}\left(u_{4} c_{4}^{\mathrm{m}} \phi^{-1}\right) u_{2}^{p} u_{3}^{q} .
$$


We define the dimensionless ambient concentrations to be

$$
u_{1}^{\mathrm{ext}}:=\left(c_{1}^{\mathrm{m}}\right)^{-1} \phi \phi^{\mathrm{a}} c_{\mathrm{CO}_{2}(g)}^{\mathrm{ext}} \quad \text { and } \quad u_{4}^{\mathrm{ext}}:=\left(c_{4}^{\mathrm{m}}\right)^{-1} \phi_{0} w^{\mathrm{ext}} .
$$

Then the boundary conditions $(7 \mathrm{e}),(8 \mathrm{~b})$ transform to

$$
\begin{aligned}
-\nabla u_{1} \cdot \nu & =W_{1}^{\mathrm{Rob}}\left(u_{1}-u_{1}^{\mathrm{ext}}\right) & & \text { at } \Gamma^{\mathrm{R}}, \\
-\delta_{4} \nabla u_{4} \cdot \nu & =W_{4}^{\mathrm{Rob}}\left(u_{4}-u_{4}^{\mathrm{ext}}\right) & & \text { at } \Gamma^{\mathrm{R}},
\end{aligned}
$$

and the non-trivial initial conditions are

$$
u_{3}(0, x)=1 \quad \text { and } \quad u_{4}(0, x)=u_{4}^{0}:=\left(c_{4}^{\mathrm{m}}\right)^{-1} \phi_{0} w^{0} .
$$

More details can be found in Meier et al. (2005).

\subsection{Carbonation depth and reaction zone}

In order to have a precise quantitative description of the carbonation progress, we define a posteriori the position of the reaction front in terms of the concentration profiles. In the literature, several definitions of the carbonation front can be found (Saetta et al. (1995), e.g.). For a discussion on this topic, we refer to Muntean (2006). We follow here the way indicated in Steffens et al. (2002) which uses the concept of a local carbonation degree. In the present setting, the local carbonation degree is measured by the dimensionless concentration $u_{5}$. Consequently, we can define the carbonation-reaction front to be the isoline which corresponds to a local carbonation degree equal to 0.9 , that is

$$
s(t):=\left\{x \in \Omega \mid u_{5}(x, t)=0.9\right\} \quad \text { for each } t>0 .
$$

When speaking about a reaction front, we tacitly assume that the reaction is located on a very thin layer. We are also interested in calculating the approximate width of this reaction layer. Let $\delta^{\text {reac }}>0$ be an appropriate lower bound for the carbonation reaction rate $\eta^{\text {reac }}$. The reaction layer is then identified with

$$
\Omega^{\text {reac }}(t):=\left\{x \in \Omega \mid \eta^{\text {reac }}(x, t)>\delta^{\text {reac }}\right\} \quad \text { for each } t>0 .
$$

It is suitable to choose $\delta^{\text {reac }}$ as $1 \%$ of the maximal value of $\eta^{\text {reac }}(x, t)$ for all $x \in \Omega$ and $t$ in the time interval of observation.

\section{Simulation results}

We consider a part of a concrete sample of width $L=3 \mathrm{~cm}$ (1d-situation, cf. fig. 1a). We solve the system (7), (8) numerically in one space-dimension 
on the interval $(0, L)$, by the finite-element method. We first derive an appropriate weak formulation of the system of 5 unknowns and accomplish a semi-discretisation in space on a uniform mesh of width $h=1 /(n-1)$ by the Galerkin method, together with a standard mass-lumping scheme. For the test and trial functions, first-order splines are used. The nonlinear $f^{\text {reac-terms }}$ are approximated by the trapezoidal rule. The resulting stiff system of $5 \times n$ odes is numerically integrated using the MATLAB ODE solver ode15s. This is a variable-order solver based on numerical differentiation formulas (NDFs). The examples in this section are obtained by choosing $n=80$.

In what follows, we present the results of a series of numerical experiments. Firstly, we validate our model by comparison with experimental results both from an accelerated carbonation test and from a natural exposure scenario. Our major aim is to show that, for a realistic choice of parameters, the simulation results are in the right range. Secondly, we show results of the parameter study, mostly with respect to the Thiele modulus. Finally, we discuss the effect of a decreasing porosity. For more related results, see also Meier et al. (2005).

\subsection{Validation of the model. Choice of model parameters}

In order to validate the model, we compare the results with experimental values from an accelerated carbonation test and from a natural exposure scenario. We start with assuming a constant concrete porosity in both experiments. For simplicity, we also assume that $\phi^{\mathrm{a}}=\phi^{\mathrm{w}}=0.5$.

The accelerated carbonation test refers to experiments by Papadakis et al. (1989). In this experiment, an OPC sample with water-to-cement ratio $R_{\mathrm{w} / \mathrm{c}}=$ 0.50 and aggregate-to-cement ratio $R_{\mathrm{a} / \mathrm{c}}=3$ is exposed to $50 \% \mathrm{CO}_{2}(\mathrm{~g}), \mathrm{RH}=$ $65 \%$, and $\vartheta=30^{\circ} \mathrm{C}$ in a carbonation chamber. This corresponds to an external $\mathrm{CO}_{2}$ concentration of $c_{\mathrm{CO}_{2}}^{\text {ext }}=8.7 \cdot 10^{-4} \mathrm{~g} / \mathrm{cm}^{3}$ and to $w^{\text {ext }}=0.033 \mathrm{~g} / \mathrm{cm}^{3}$. Cf. Steffens (2000), the initial amount of $\mathrm{Ca}(\mathrm{OH})_{2}$ available to reaction in OPC concrete can be estimated by $\phi \phi^{\mathrm{w}} c_{\mathrm{Ca}(\mathrm{OH})_{2}}^{0}=0.077 \mathrm{~g} / \mathrm{cm}^{3}$. The initial porosity is calculated as $\phi=0.54$. The initial humidity of the sample is assumed to equal the external value. In dimensionless quantities, this corresponds to $u_{4}^{0}=u_{4}^{\text {ext }}=0.63$. Values for the diffusivities have been reported in Papadakis et al. (1989) to be of the order of $10--50 \mathrm{~cm}^{2} / \mathrm{d}$ for $D_{\mathrm{CO}_{2}(g)}$ and of the order of $10^{-4} \mathrm{~cm}^{2} / \mathrm{d}$ for $D_{\mathrm{CO}_{2}}$ and $D_{\mathrm{Ca}(\mathrm{OH})_{2}}$. In the simulations, we use $D_{\mathrm{CO}_{2}(g)}=$ $12 \mathrm{~cm}^{2} / \mathrm{d}$ and $D_{\mathrm{CO}_{2}}=D_{\mathrm{Ca}(\mathrm{OH})_{2}}=10^{-4} \mathrm{~cm}^{2} / \mathrm{d}$. Transport and production of moisture is not considered in the model in Papadakis et al. (1989). From Steffens (2000), we find $D_{\mathrm{H}_{2} \mathrm{O}}=10^{-2} \mathrm{~cm}^{2} /$ d.

One of the remaining issues is a proper identification of the (temperaturedependent) reaction constant $C^{\text {reac }}$, the mass-transfer constants $C_{\mathrm{CO}_{2}(g)}^{\mathrm{Rob}}, C_{\mathrm{H}_{2} \mathrm{O}}^{\mathrm{Rob}}$, 
and the gas-liquid mass-transfer constant $C^{\text {ex }}$. A measured value for $C^{\text {reac }}$ can be found in Steffens (2000). Due to the non-standard choice of Robin boundary conditions in our model, the other three parameters are rarely found in literature. In order to point out some extreme cases, these parameters are chosen sufficiently large such that the associated transfer process is nearly in equilibrium. In this way, we eliminate additional delay effects due to a slow exchange at the external boundary and at the internal gas-liquid interfaces. The exact values used in the simulations are listed in table 2 .

Table 2

\begin{tabular}{c||c|c|c|c|} 
Parameter & $C^{\text {reac }}$ & $C_{\mathrm{CO}_{2}(g)}^{\mathrm{Rob}}$ & $C_{\mathrm{H}_{2} \mathrm{O}}^{\mathrm{Rob}}$ & $C^{\mathrm{ex}}$ \\
\hline Unit & $\frac{\mathrm{mol} \mathrm{cm}^{3}}{\mathrm{~g}^{2} \mathrm{~d}}$ & $\mathrm{~cm} / \mathrm{d}$ & $\mathrm{cm} / \mathrm{d}$ & $\mathrm{d}^{-1}$ \\
\hline Value (accelerated) & 461 & $10^{5}$ & $10^{7}$ & $10^{3}$ \\
Value (natural) & 1220 & $10^{5}$ & $10^{7}$ & $10^{3}$
\end{tabular}

Numerical values of the parameters $C^{\text {reac }}, C_{\mathrm{CO}_{2}(g)}^{\mathrm{Rob}}, C_{\mathrm{H}_{2} \mathrm{O}}^{\mathrm{Rob}}$ and $C^{\text {ex }}$ used in the simulations.

The dimensionless concentration profiles for all species and the carbonation depth are shown in fig. 2. The length- and time-axis of the plots are given in days and $\mathrm{cm}$. From the $\mathrm{CO}_{2}$ profiles (fig. $2 \mathrm{a}+\mathrm{b}$ ) and from the $\mathrm{Ca}(\mathrm{OH})_{2}$ and $\mathrm{CaCO}_{3}$ profiles (figs. $2 \mathrm{c}+\mathrm{e}$ ), the progress of the carbonation front into the material can be seen. The decay of the reactants $\mathrm{Ca}(\mathrm{OH})_{2}$ and $\mathrm{Ca}(\mathrm{CO})_{3}$ near the reaction layer is quite steep, while that of $\mathrm{CO}_{2}(a q)$ and $\mathrm{CO}_{2}(g)$ is not as steep. The similar profiles of $\mathrm{CO}_{2}(g)$ and $\mathrm{CO}_{2}(a q)$ show that the exchange between them is almost in equilibrium. In fig. 2e, the (dimensionless) moisture variable $u_{4}$ is shown. While far inside the sample the moisture level does not change during carbonation, a considerable amount of water is produced inside the reaction layer. The highly inhomogeneous moisture profiles indicate that the water produced by reaction can play a significant role for the carbonation process. Finally, in fig. 2f, the carbonation depth (defined in section 3.1) is plotted. It can be observed that the experimental values of the carbonation depth are very well recovered by the simulation.

In our second numerical experiment, we compare our results with measurements under natural conditions reported in Wierig (1984). His data refers to a CEM I concrete sample with $\mathrm{R}_{\mathrm{w} / \mathrm{c}}=0.60$ placed outdoors under roof. The climatic conditions in Northern Germany correspond to average annual values of $\mathrm{RH}=78 \%$ and $\vartheta=9^{\circ} \mathrm{C}$. For the simulation, these averaged values have been used for the determination of the parameters and of the (constant) boundary conditions. This corresponds to $u_{4}^{0}=u_{4}^{\text {ext }}=0.67$. The atmospheric $\mathrm{CO}_{2}$ concentration is $c_{\mathrm{CO}_{2}}^{\text {ext }}=5.4 \cdot 10^{-7} \mathrm{~g} / \mathrm{cm}^{3}$. The diffusion coefficient of $\mathrm{CO}_{2}(\mathrm{~g})$ in this experiment is estimated as $D_{\mathrm{CO}_{2}(g)}=16 \mathrm{~cm}^{2} / \mathrm{d}$. In fig. 3, the corresponding profiles and the carbonation depth are plotted. We observe a similar behaviour of the profiles as for the accelerated case, but over a different time span. The only profile which is highly different is that of moisture (cf. fig. $2 \mathrm{~d}$ vs. fig. $3 \mathrm{~d}$ ). 


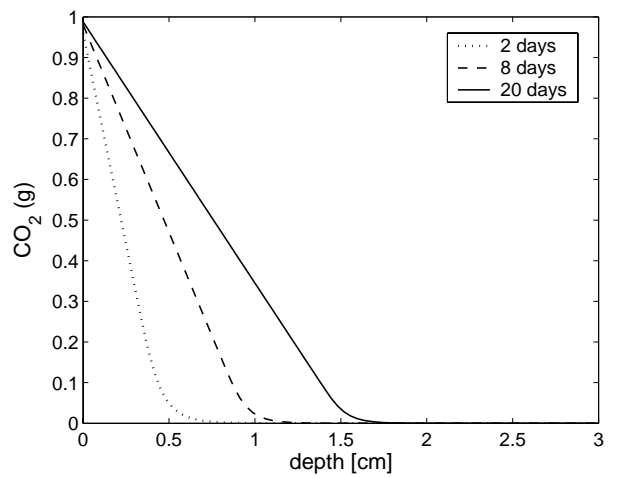

a) $\mathrm{CO}_{2}(g)$

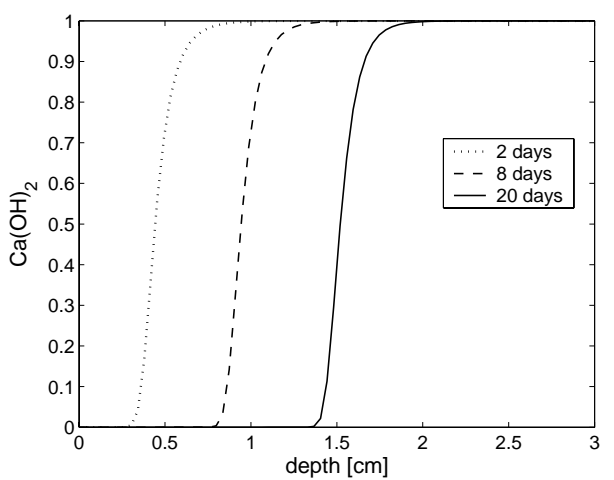

c) $\mathrm{Ca}(\mathrm{OH})_{2}(a q)$

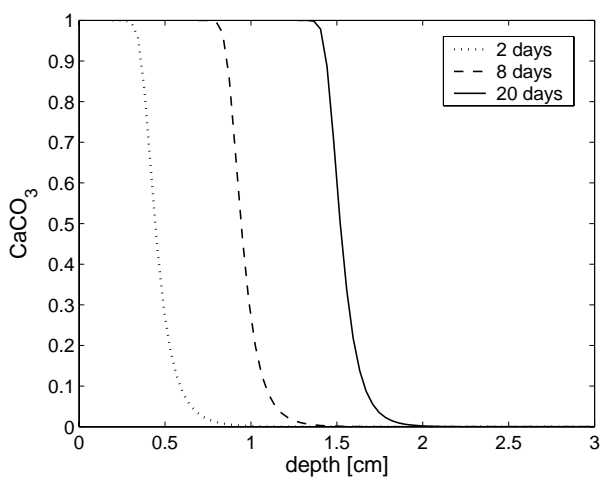

e) $\mathrm{CaCO}_{3}(a q)$

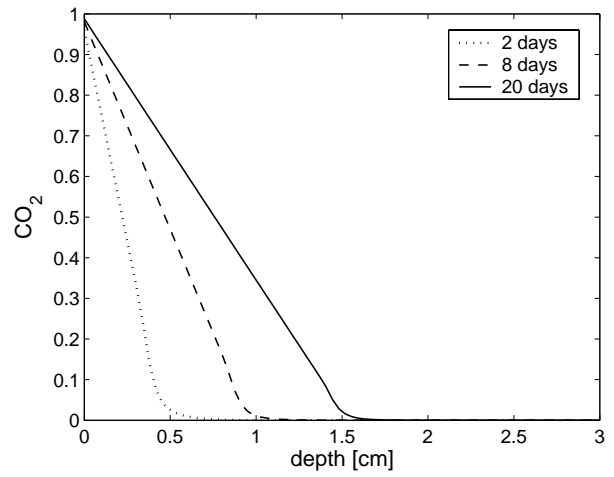

b) $\mathrm{CO}_{2}(a q)$

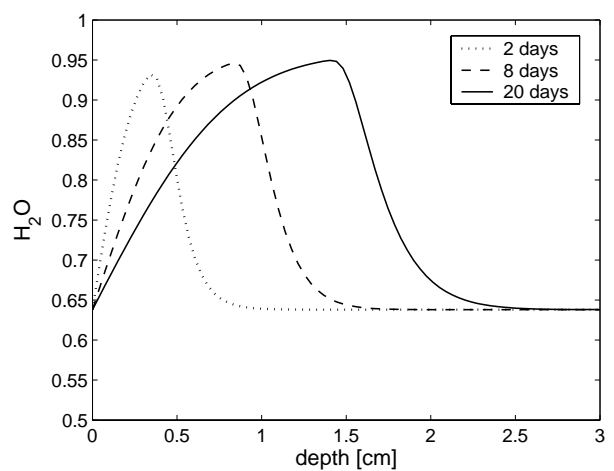

d) moisture $\left(u_{4}\right)$

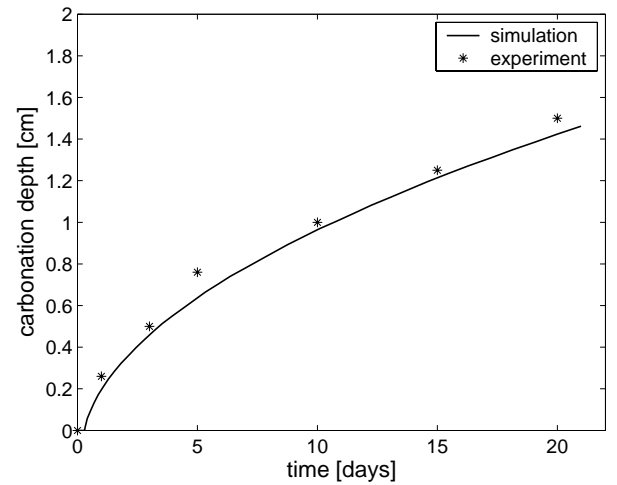

f) carbonation depth

Fig. 2. Dimensionless concentration profiles for the accelerated test.

Here we observe lower profiles as in the accelerated case. The reason for this is the fact that the whole reaction-diffusion process is slower and, therefore, the produced moisture has enough time to leave the sample. The experimental values for the carbonation depth (fig. 3f) are in the range of the computed ones. The discrepancy from the first-time values may be explained by nondiffusive transport mechanisms not captured by our model, which can lead to 


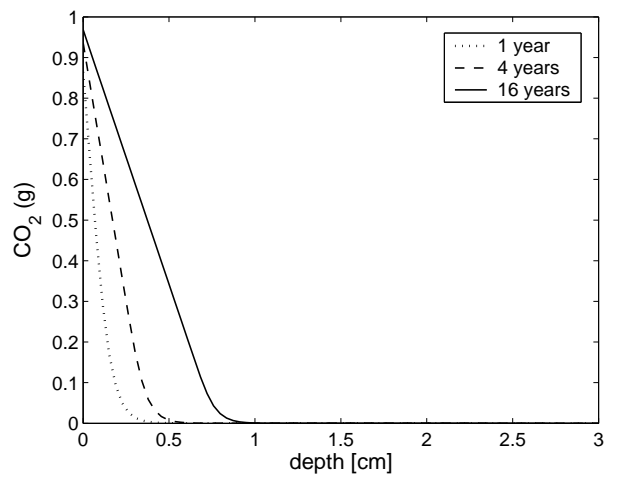

a) $\mathrm{CO}_{2}(g)$

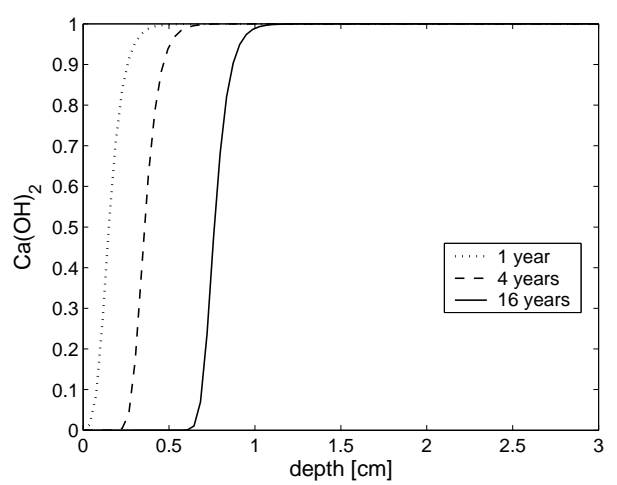

c) $\mathrm{Ca}(\mathrm{OH})_{2}(a q)$

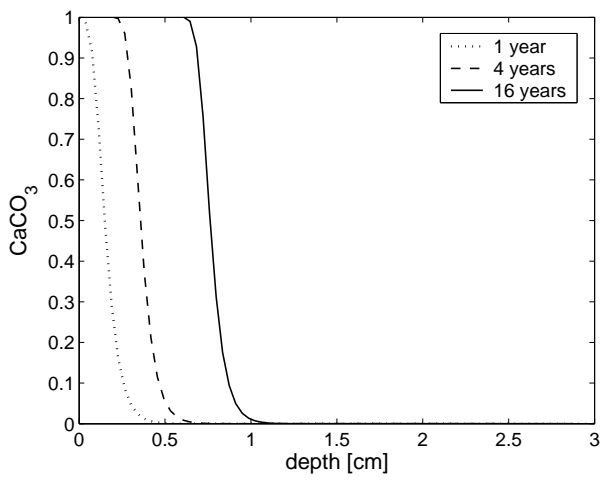

e) $\mathrm{CaCO}_{3}(a q)$

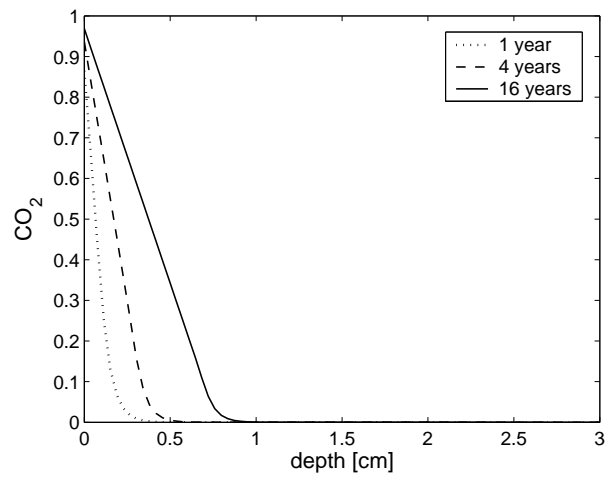

b) $\mathrm{CO}_{2}(a q)$

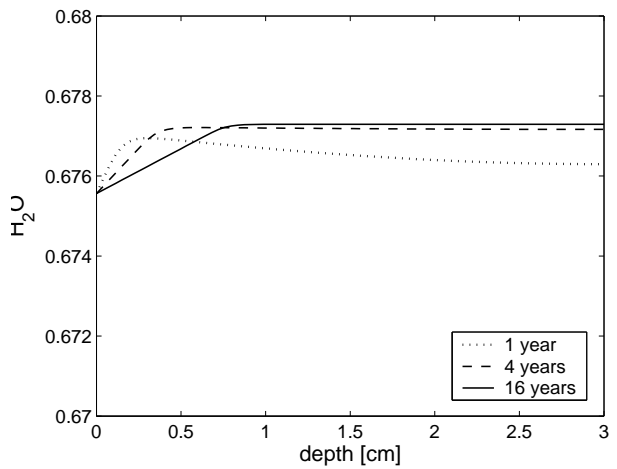

d) moisture $\left(u_{4}\right)$

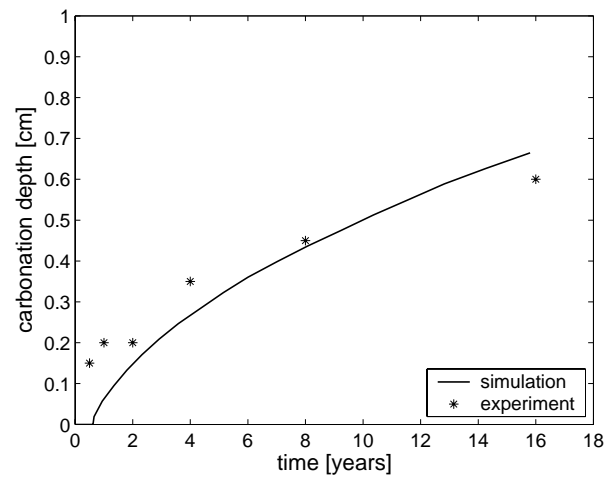

f) carbonation depth

Fig. 3. Dimensionless concentration profiles for the natural exposure scenario.

an initially fast carbonation reaction near the boundary. See van Balen and van Gemert (1994) for a discussion of this topic. However, these boundary effects are often ignored when comparing computational results with measured data. 


\subsection{Influence of the Thiele modulus}

We perform a parameter study concerning the effect of the Thiele modulus $\Phi^{2}$ and of the mass-transfer coefficient of $\mathrm{CO}_{2}$-absorption. We use the parameter values from the accelerated carbonation test. The Thiele modulus relates the rapidness of the carbonation reaction to the diffusion time of $\mathrm{CO}_{2}(g)$. In the accelerated carbonation scenario we notice a fast reaction, i.e. $\Phi^{2} \approx 993 \gg 1$. In this regime, a sensitivity analysis shows that the carbonation depth is rather stable with respect to the exact value of $\Phi^{2}$ (fig. 4a). A variation of $\Phi^{2}$ by $10 \%$ leads to a variation of the carbonation depth after 20 days by about $3 \%$.

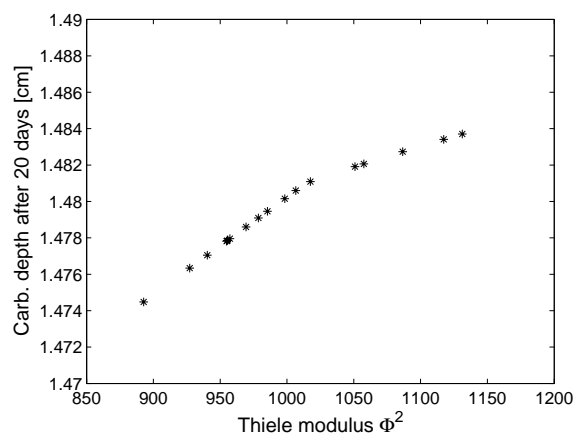

a)

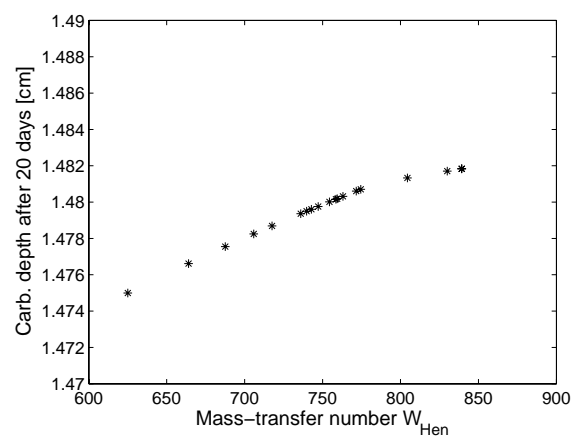

b)

Fig. 4. Sensitivity analysis with respect to $\Phi^{2}$ (a) and with respect to $W^{\text {Hen }}$ (b).

Moreover, we are interested in the changes of the results when choosing a much smaller value of the Thiele modulus $\left(\Phi^{2}=99\right)$, and then a much larger one $\left(\Phi^{2}=9930\right)$, while leaving all other parameters unchanged. We keep track of the evolution of the reaction rate and the carbonation depth at all three cases. For comparison, the results for $\Phi^{2}=993$ are plotted in fig. $5 \mathrm{c}+\mathrm{d}$.

For a much smaller Thiele modulus (figs. 5a+b), the advancement of the carbonation front is much slower. The maximum of the reaction rate is correspondingly much smaller at all times, while the width of the reaction zone is greater. In addition, a large transient time occurs before the carbonation layer is formed. For the much larger Thiele modulus (figs. $5 \mathrm{e}+\mathrm{f}$ ), the advancement of the carbonation front is slightly faster. The maximum of the reaction rate is much larger at any given time and the width of the reaction zone is smaller. The transient time is negligible in this setting, i.e. the reaction layer is formed and begins moving almost instantaneously. In all three cases, it can be observed that the reaction rate decreases with time and the width of the reaction layer remains fairly constant.

The required computation time basically depends on the size of the Thiele modulus. For large values of $\Phi^{2}$, the system of first order ODEs in time, which is obtained after the semi-discretisation in space, is highly stiff. This requires 
the choice of very small time steps. Using an implicit scheme with adaptive choice of the time steps, it can be solved in a satisfactory way. Another numerical problem originating from a high Thiele modulus is the occurrence of (naturally) steep gradients of the concentration profiles near the internal layer. In order to catch effects in this zone, a sufficiently high resolution in space is needed.

By an analogous parameter study with respect to the (gas-liquid) mass transfer number $W^{\text {Hen }}$, we note that for large values $\left(W^{\text {Hen }} \approx 750\right)$ the model output is unsensitive with respect to the exact choice of $W^{\text {Hen }}$ (fig. 4b). A variation of $W^{\text {Hen }}$ by $10 \%$ leads to a variation of the carbonation depth after 20 days by $1-2 \%$. However, for smaller values of $W^{\text {Hen }}$, we observe a slight broadening of the reaction front that does not alter the evolution of the carbonation front significantly. 


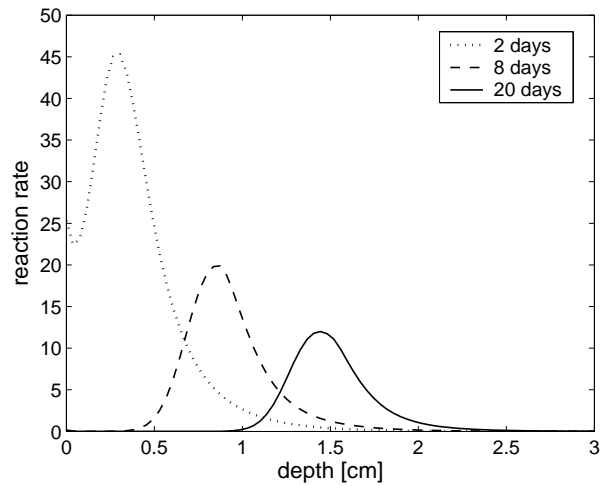

a) reaction rate, $\Phi^{2}=99$

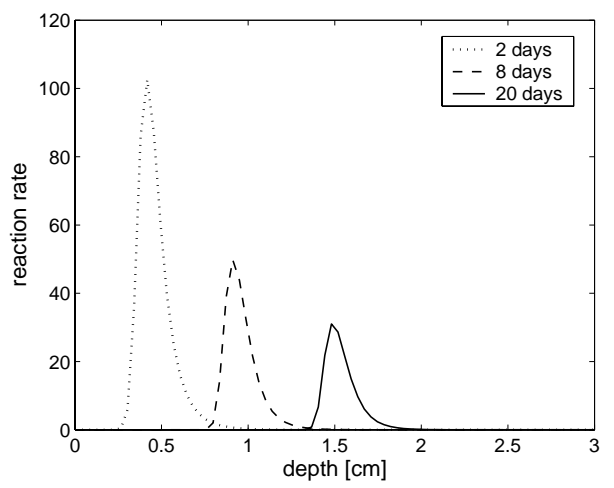

c) reaction rate, $\Phi^{2}=993$

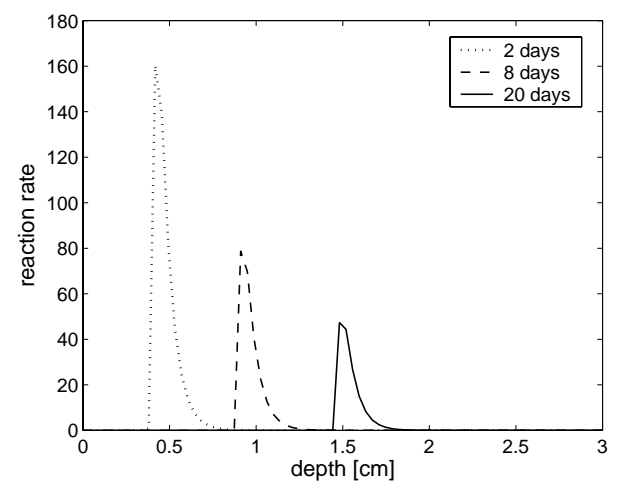

e) reaction rate, $\Phi^{2}=9930$

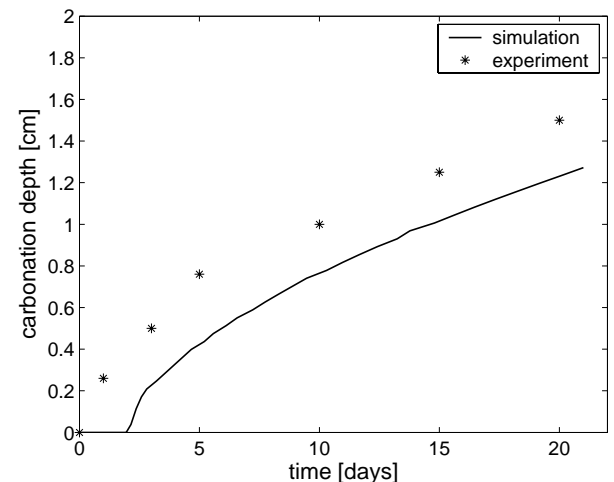

b) carbonation depth, $\Phi^{2}=99$

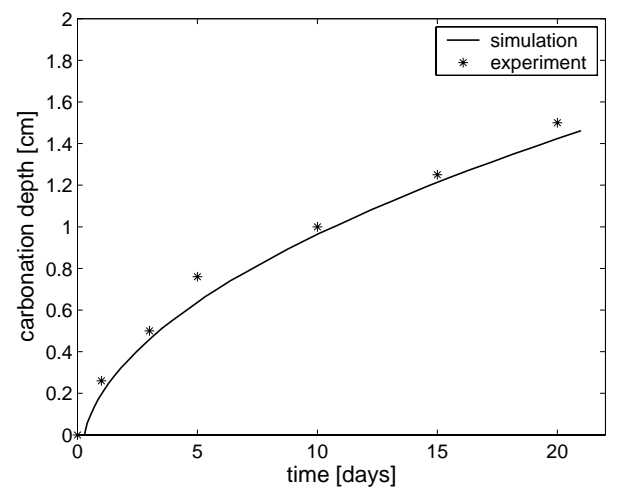

d) carbonation depth, $\Phi^{2}=993$

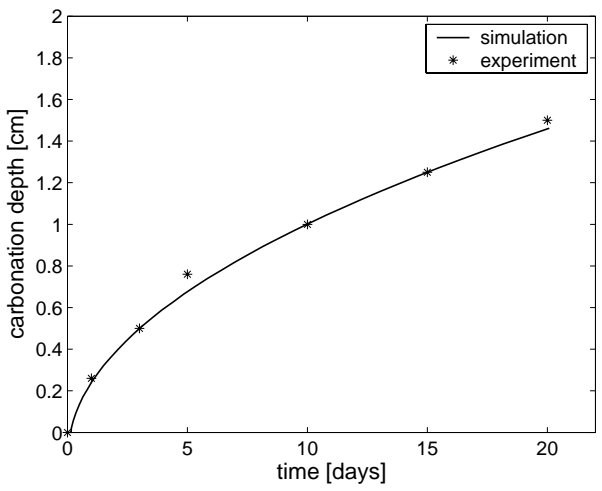

f) carbonation depth, $\Phi^{2}=9930$

Fig. 5. Profiles of reaction rate and carbonation depth for different values of $\Phi^{2}$. 


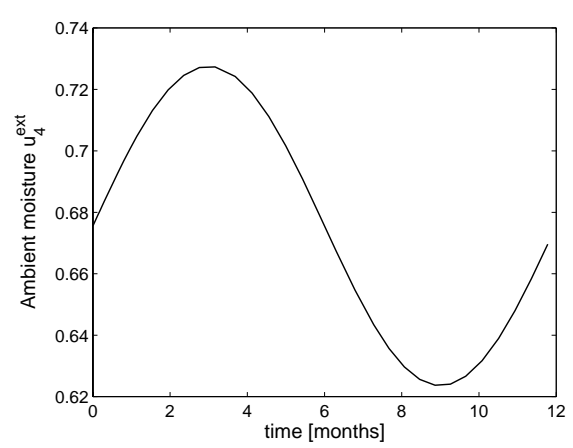

a) external moisture $u_{4}^{\text {ext }}$

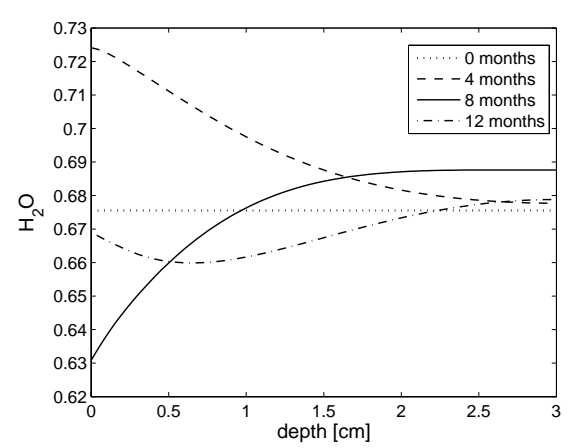

b) moisture $u_{4}$

Fig. 6. (a) Variable external moisture profile over 1 year. (b) Resulting (dimensionless) moisture profiles $\left(u_{4}\right)$ inside the sample.

\subsection{Effects of variable boundary conditions}

In the preceding numerical experiments, the external humidity was constant. It is known that in case of natural carbonation, seasonal variations in the exposure have a strong influence on the carbonation progress. In Steffens (2000), a relative humidity range between $71 \%$ in May and $86 \%$ in December is proposed for the northwestern part of Germany. We therefore simulate the natural carbonation scenario again, where the averaged external moisture $u_{4}^{\text {ext }}$ is replaced by a periodic profile in the corresponding range $u_{4}^{\text {ext }} \in[0.62,0.73]$ (see fig. 6a). Other possibly important climatic effects like change in temperature or rainfall are neglected in this study.

The resulting moisture profiles within one year are shown in figure 6b. A wetting period in the first four months is followed by a drying period. After the wetting period, the humidity inside the sample is large $\left(u_{4}>0.7\right)$ near the exposed boundary, but has not yet grown too much far away from that boundary. This happens afterwards, during the drying period when the external humidity is lower than the average value. It can also be observed that, after one cycle, the moisture in the interior of the sample is not uniform again.

However, at the present stage we are not able to recover accurately the effect of these drying and wetting periods on the carbonation process. This is mainly due to the simplifications made in the modelling of the $\mathrm{CO}_{2}(g)$ transport.

\subsection{Effects of time-dependent porosity}

In our last numerical experiment, we study the influence on the carbonation progress when an exponential decrease of the porosity as discussed in section 2.2 is taken into account. Here we use the parameters referring to natural 


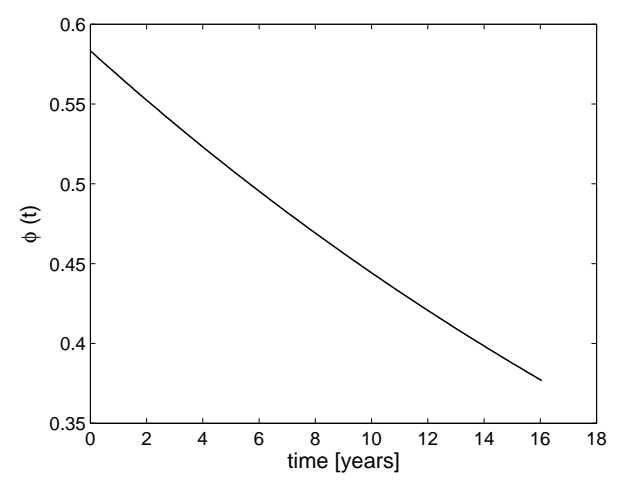

a) porosity

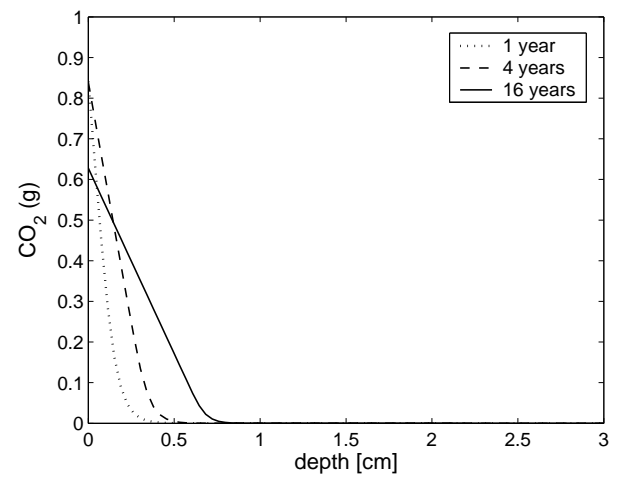

b) $\mathrm{CO}_{2}(g)$

Fig. 7. (a) Exponentially decreasing porosity (cf. (3)) and (b) simulated $\mathrm{CO}_{2}(g)$ profiles for natural exposure with decreasing porosity.

carbonation. This choice yields a decrease of the concrete porosity by about one third of the initial value after 16 years (fig. 7a), which is in the range of experimental observations (Bier (1988)).

The resulting $\mathrm{CO}_{2}(g)$ profiles are illustrated in fig. 7b. Compared to the setting with constant porosity (fig. 3a) no changes are observed for small times. Since the initial porosity $\phi_{0}$ coincides with the constant value from the standard setting, this fact is not surprising. However, for larger times, the total concentration of $\mathrm{CO}_{2}$ entering the sample from the left boundary decreases due to the lower porosity, and, additionally, the transport becomes slower. Consequently, the velocity of the reaction layer becomes smaller and the advancement of the front slows down. This effect can be seen in fig. $8 \mathrm{a}+\mathrm{b}$. The carbonation depth after 16 years is smaller than in the simulations with constant porosity. The late-time measurements are thereby better recovered by the simulation with decreasing porosity. These observations agree with the predictions by asymptotic penetration laws such as that one by Papadakis et al. (1989). 


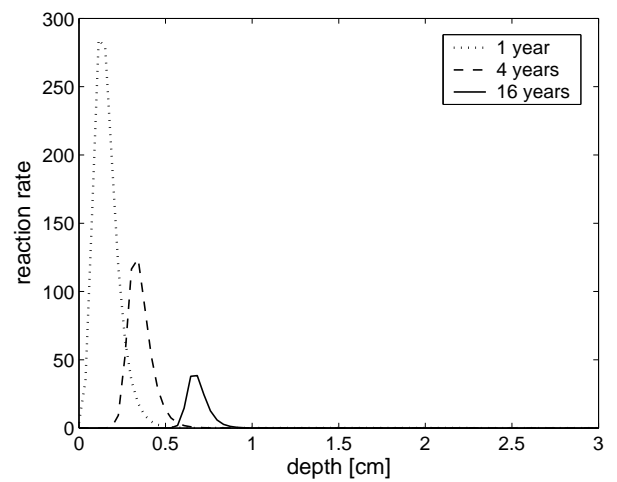

a) reaction rate

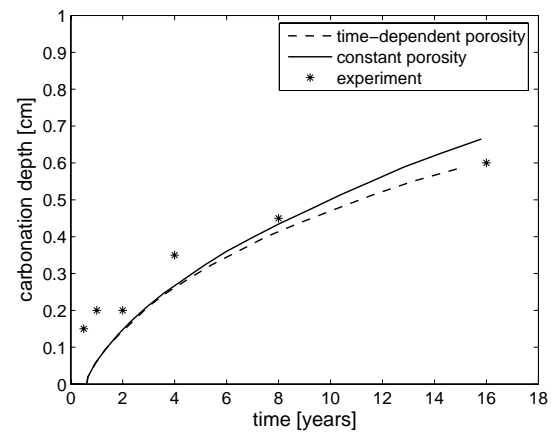

b) carbonation depth

Fig. 8. Reaction rate and carbonation depth for natural exposure with decreasing porosity. 


\section{Conclusions}

A mathematical model has been formulated to describe the main reactiondiffusion mechanisms which affect the carbonation of concrete. Besides the influence of moisture produced by reaction, the model also includes a timedependent porosity. A proper dimensional analysis showed that the entire process is determined by a few dimensionless numbers including the Thiele modulus $\Phi^{2}$ which is large in this setting.

In both the accelerated and natural scenario, the simulated carbonation depth lies in the range of the experimental measurements. The localisation of the carbonation reaction on a thin layer can be observed for a wide range of parameters. This internal layer can be seen as a zone where a noticeable carbonation reaction takes place and near which steep gradients in the reactant profiles occur. The position and size of the layer are defined in terms of the dimensionless quantities in section 3.1. We observed that the width of the reaction layer strongly depends on the size of the Thiele modulus $\Phi^{2}$, but is also related to the magnitude of the $\mathrm{CO}_{2}$ absorption speed. It can be observed that the layer width increases if $W^{\mathrm{Hen}}$ or $\Phi^{2}$ decreases. A noticeable spreading or sharpening in time does not occur. The speed of the layer increases for large $\Phi^{2}$, with a tendency to converge to a certain limit. The speed is less affected by the number $W^{\text {Hen }}$. The results validate the use of moving-boundary models for concrete carbonation for a wide range of parameters.

The above observations have been made in those numerical experiments in which a constant porosity and constant external exposure conditions were proposed. The decrease in porosity leads to a similar behaviour, but with a decreasing speed of the reaction layer for large times as it was also reported by Bier (1988), e.g. Consequently, the whole carbonation process slows down for large times, leading to a better coverage of the experimental values. Climatic effects, modelled via a periodic external humidity, lead to the expected drying and wetting periods inside the sample. Their effect on the carbonation process cannot be recovered by the model in its present form.

We finally note that the required computation time is related to the Thiele modulus, too. For large values of $\Phi^{2}$, the PDE system becomes very stiff and small time steps are needed. This issue is particularly eminent for an implementation in 2D or 3D for complex geometries. The use of adaptive finite-element methods can reduce the computation time by allowing a coarse spatial grid far away from the reaction layer. For a first approach in this direction, we refer to Schmidt et al. (2005). 


\section{Acknowledgements}

This work has been supported by the Deutsche Forschungsgemeinschaft (DFG) with a grant through the special priority program SPP1122 Prediction of the Course of Physicochemical Damage Processes Involving Mineral Materials. We are also grateful to the state of Bremen for funding this work via the PhD program Scientific Computing in Engineering as well as to the German National Academic Foundation.

\section{Notation}

\begin{tabular}{|c|c|c|}
\hline Parameter & Unit & Description \\
\hline$R_{\mathrm{w} / \mathrm{c}}$ & - & water-to-cement ratio \\
\hline$R_{\mathrm{a} / \mathrm{c}}$ & - & aggregate-to-cement ratio \\
\hline$\phi$ & - & concrete porosity \\
\hline$\phi_{0}$ & - & initial concrete porosity \\
\hline$\phi^{\mathrm{a}}$ & - & volume fraction of air-filled pores \\
\hline$\phi^{\mathrm{w}}$ & - & volume fraction of water-filled pores \\
\hline$m_{\nu}$ & $\mathrm{g} / \mathrm{mol}$ & molecular weight of species $\nu$ \\
\hline$\rho_{\nu}$ & $\mathrm{g} / \mathrm{cm}^{3}$ & density of species $\nu$ \\
\hline$c_{\nu}$ & $\mathrm{g} / \mathrm{cm}^{3}$ & mass concentration of species $\nu$ \\
\hline$w$ & $\mathrm{~g} / \mathrm{cm}^{3}$ & moisture concentration \\
\hline $\mathrm{RH}$ & - & relative humidity \\
\hline$c_{\mathrm{CO}_{2}}^{\mathrm{ext}}$ & $\mathrm{g} / \mathrm{cm}^{3}$ & ambient concentration of $\mathrm{CO}_{2}(g)$ \\
\hline$w^{\text {ext }}$ & $\mathrm{g} / \mathrm{cm}^{3}$ & ambient concentration of moisture \\
\hline$c_{\nu}^{0}$ & $\mathrm{~g} / \mathrm{cm}^{3}$ & initial concentration of species $\nu$ \\
\hline$w^{0}$ & $\mathrm{~g} / \mathrm{cm}^{3}$ & initial concentration of moisture \\
\hline
\end{tabular}




\begin{tabular}{|c|c|c|}
\hline$D_{\nu}$ & $\mathrm{cm}^{2} / \mathrm{d}$ & diffusivity of species $\nu$ \\
\hline$f^{\text {reac }}$ & $\mathrm{mol} /\left(\mathrm{cm}^{3} \mathrm{~d}\right)$ & production term by carbonation \\
\hline$f^{\mathrm{Hen}}$ & $\mathrm{g} /\left(\mathrm{cm}^{3} \mathrm{~d}\right)$ & production term by $\mathrm{CO}_{2}$-dissolution \\
\hline$C^{\text {reac }}$ & $\mathrm{mol} \mathrm{cm} \mathrm{cm}^{3} /\left(\mathrm{g}^{p+q} \mathrm{~d}\right)$ & carbonation reaction constant \\
\hline$C^{\text {Henry }}$ & - & dimensionless Henry constant \\
\hline$C^{\mathrm{ex}}$ & $1 / \mathrm{d}$ & $\begin{array}{l}\text { gas-liquid mass transfer coefficient for } \\
\mathrm{CO}_{2}(g)\end{array}$ \\
\hline$C_{\nu}^{\mathrm{Rob}}$ & $\mathrm{cm} / \mathrm{d}$ & mass transfer coefficient of species $\nu$ \\
\hline$\vartheta$ & $\mathrm{K}$ & temperature \\
\hline$L$ & $\mathrm{~cm}$ & width of the sample \\
\hline$\nu$ & - & unit normal vector directed outward \\
\hline Parameter & Unit & Description \\
\hline$T$ & $\mathrm{~d}$ & characteristic diffusion time \\
\hline$c_{i}^{\mathrm{m}}$ & $\mathrm{g} / \mathrm{cm}^{3}$ & maximal concentration of species $i$ \\
\hline$u_{i}$ & - & $\begin{array}{l}\text { dimensionless concentration of species } \\
i\end{array}$ \\
\hline$u_{i}^{\text {ext }}$ & - & $\begin{array}{l}\text { dimensionless ambient concentration of } \\
\text { species } i\end{array}$ \\
\hline$\Phi^{2}$ & - & Thiele modulus \\
\hline$W^{\mathrm{Hen}}$ & - & $\begin{array}{l}\text { dimensionless number of } \mathrm{CO}_{2}^{-} \\
\text {dissolution }\end{array}$ \\
\hline$\eta^{\text {reac }}$ & - & $\begin{array}{l}\text { dimensionless carbonation reaction } \\
\text { rate }\end{array}$ \\
\hline $\bar{\kappa}$ & - & bulk carbonation degree \\
\hline$s$ & - & $\begin{array}{l}\text { position of the carbonation-reaction } \\
\text { front }\end{array}$ \\
\hline
\end{tabular}




\section{References}

Bier, T. A., 1988. Karbonatisierung und Realkalisierung von Zementstein und Beton. Ph.D. thesis, University Fridericiana in Karlsruhe, Schriftenreihe des Instituts für Massivbau und Baustofftechnologie. Editors: J. Eibl, H. K. Hilsdorf .

Böhm, M., Kropp, J., Muntean, A., 2003. On a prediction model for concrete carbonation based on moving interfaces - interface concentrated reactions. Berichte aus der Technomathematik 03-03, ZeTeM, University of Bremen.

Chaussadent, T., 1999. États de lieux et réflexions sur la carbonatation du beton armé. Tech. rep., Laboratoire Central de Ponts et Chaussées, Paris.

Froment, G. F., Bischoff, K. B., 1990. Chemical Reactor Analysis and Design, 2nd Edition. Wiley Series in Chemical Engineering. John Wiley and Sons.

Grunewald, J., 1997. Diffusiver und konvektiver Stoff- und Energietransport in kapillarporösen Baustoffen. Ph.D. thesis, Technical University of Dresden.

Ishida, M., Wen, C. Y., 1968. Comparison of kinetic and diffusional models for solid-gas reactions. AIChE J. 14 (2), 311-317.

Ishida, T., Maekawa, K., 2001. Modeling of $\mathrm{pH}$ profile in pore water based on mass transport and chemical equilibrium theory. Concrete Library of JSCE 37, 131-146.

Ishida, T., Maekawa, K., Soltani, M., 2004. Theoretically identified strong coupling of carbonation rate and thermodynamic moisture states in micropores of concrete. Journal of Advanced Concrete Technology 2 (2), 213-222.

Kropp, J., 1995. Relations between transport characteristics and durability. In: Kropp, J., Hilsdorf, H. K. (Eds.), Performance Criteria for Concrete Durability. RILEM Report 12. E and FN Spon Ed., pp. 97-137.

Meier, S. A., Peter, M. A., Böhm, M., 2005a. A two-scale modelling approach to reaction-diffusion processes in porous materials. Computational Materials Science (in press).

Meier, S. A., Peter, M. A., Muntean, A., Böhm, M., 2005. Modelling and simulation of concrete carbonation with internal layers. Berichte aus der Technomathematik 05-02, ZeTeM, University of Bremen.

Muntean, A., 2006. A Moving-Boundary Problem: Modeling, Analysis and Simulation of Concrete Carbonation. Ph.D. thesis, University of Bremen, Cuvillier Verlag, Göttingen.

Muntean, A., Böhm, M., 2004a. On a moving reaction layer model for the prediction of the service life of concrete structures. In: Yagawa, G., Kikuchi, M., Atanasiu, G. M., Bratianu, C. (Eds.), Proc. Int. Conf. Performance based Engineering for 21st Century. Technical University of Iasi, Romania, pp. $72-77$.

Muntean, A., Böhm, M., 2004b. On a prediction model for the service life of concrete structures based on moving interfaces. In: Stangenberg, F., Bruhns, O. T., Hartmann, D., Meschke, G. (Eds.), Proc. 2nd Int. Conf. LifetimeOriented Design Concepts. Ruhr University Bochum, Germany, pp. 209218. 
Muntean, A., Böhm, M., 2006. Dynamics of a moving reaction interface in a concrete wall. In: et al., J. F. R. (Ed.), Free and Moving Boundary Problems. Theory and Applications. Vol. 154. Birkhäuser, pp. 317-326.

Papadakis, V. G., Vayenas, C. G., Fardis, M. N., 1989. A reaction engineering approach to the problem of concrete carbonation. AIChE Journal 35, 16391650.

Peter, M. A., Muntean, A., Meier, S. A., Böhm, M., 2006. Parametric study of the competition of several carbonation reactions in concrete, submitted to Cement and Concrete Research.

Saeki, T., Nagataki, S., June 1997. Effect of hydration of cement after initial curing on carbonation rate. In: Proc. Int. Conf. Engineering Materials. pp. 315-329.

Saeki, T., Ohga, H., Nagataki, S., 1990. Change in micro-structure of concrete due to carbonation. Concrete Library of JSCE 420 (V-13), 1-12.

Saetta, A. V., Schrefler, B. A., Vitaliani, R. V., 1995. 2D model for carbonation and moisture/heat flow in porous materials. Cement and Concrete Research 25 (8), 1703-1712.

Schmidt, A., Muntean, A., Böhm, M., 2005. Numerical experiments with selfadaptive finite element simulations in $2 \mathrm{D}$ for the carbonation of concrete. Berichte aus der Technomathematik 05-01, ZeTeM, University of Bremen.

Sisomphon, K., 2004. Influence of pozzolanic material additions on the development of the alkalinity and the carbonation behaviour of composite cement pastes and concretes. Ph.D. thesis, TU Hamburg-Harburg.

Steffens, A., 2000. Modellierung von Karbonatisierung und Chloridbindung zur numerischen Analyse der Korrosionsgefährdung der Betonbewehrung. Ph.D. thesis, Institute for Statics, Technical University Braunschweig.

Steffens, A., Dinkler, D., Ahrens, H., 2002. Modeling carbonation for corrosion risk prediction of concrete structures. Cement and Concrete Research 32, 935-941.

Taylor, H. F. W., 1997. Cement Chemistry. Thomas Telford Publishing, London.

van Balen, K., 2005. Carbonation reaction of lime, kinetics at ambient temperature. Cement and Concrete Research 35 (4), 647-657.

van Balen, K., van Gemert, D., 1994. Modelling lime mortar carbonation. Materials and Structures 27, 393-398.

Weber, W. A., DiGiano, F. A., 1996. Process Dynamics in Environmental Systems. Environmental Science and Technology. John Wiley and Sons, Inc.

Wierig, H.-J., 1984. Longtime studies on the carbonation of concrete under normal outdoor exposure. In: Proc. RILEM, Hannover University. pp. 239249 . 